\title{
A FEMINIZAÇÃO DA POBREZA NO BRASIL E SEUS DETERMINANTES
}

The feminization of poverty in Brazil and its determinants

Virginia de Souza

Camila Penteado

Rafaelly do Nascimento

Augusta Pelinski Raiher 


\title{
A FEMINIZAÇÃO DA POBREZA NO BRASIL E SEUS DETERMINANTES
}

\author{
The feminization of poverty in Brazil and its determinants
}

\author{
Virginia de Souza \\ Camila Penteado \\ Rafaelly do Nascimento \\ Augusta Pelinski Raiher
}

\begin{abstract}
Resumo: Este artigo teve como objetivo analisar a feminização da pobreza nos anos de 2001 e 2015 no Brasil, identificando os fatores associados a esse processo. Como metodologia, construiu-se uma medida para a pobreza considerando uma abordagem mista (quantitativo e qualitativo), utilizando os dados da Pnad. Na sequência, estimou-se modelos Logit visando identificar os fatores que elevam a probabilidade de se ter a feminização da pobreza no Brasil. O estudo apontou que houve diminuição dos níveis de pobreza no Brasil, para os anos de 2001 e 2015. No entanto, ocorreu um aumento na diferença entre o percentual de domicílios chefiados por mulheres inseridas na pobreza versus os chefiados por homens. Ademais, dentre os determinantes dessa feminização identificou-se a baixa escolaridade, a falta de trabalho, a presença de criança no domicílio, dentre outros fatores, identificando uma maior probabilidade de se inserir nesse processo as mulheres negras/pardas/indígenas da região Norte/Nordeste do Brasil.
\end{abstract}

Palavras-chaves: Feminização da pobreza. Determinantes. Brasil.

\begin{abstract}
This article aimed to analyze the feminization of poverty in the years 2001 and 2015 in Brazil, identifying the factors associated with this process. As methodology, a poverty measure was constructed considering a mixed approach (quantitative and qualitative), using PNAD data. Logit models were then used to identify the factors that increase the likelihood of the feminization of poverty in Brazil. The study pointed to a decrease in poverty levels in Brazil for the years 2001 and 2015. However, there was an increase in the difference between the percentage of households headed by women inserted in poverty versus those headed by men. In addition, among the determinants of this feminization, low levels of schooling, lack of work, presence of children, among other factors, identifying a higher probability to insert in this process black / brown / indigenous women in the North / Northeast region of Brazil.
\end{abstract}

Key words: Feminization of poverty; Determinants; Brazil.

Resumen: Este artículo tuvo como objetivo analizar la feminización de la pobreza en 2001 y 2015 en Brasil, identificando los factores asociados con este proceso. Como metodología, se construyó una medida de pobreza considerando un enfoque mixto (cuantitativo y cualitativo), utilizando datos de Pnad. A continuación, se estimaron los modelos Logit para identificar los factores que aumentan la probabilidad de feminización de la pobreza en Brasil. El estudio encontró que hubo una disminución en los niveles de pobreza en Brasil para los años 2001 y 2015. Sin embargo, hubo un aumento en la diferencia entre el porcentaje de hogares encabezados por mujeres en situación de pobreza frente a los encabezados por hombres. Además, entre los determinantes de esta feminización se encuentran la baja educación, la falta de trabajo, la presencia de niños en el hogar, entre otros factores, que identifican una mayor probabilidad de incluir mujeres negras / marrones / indígenas de la región Norte / Sur. Nordeste de Brasil.

Palabras clave: Feminización de la pobreza. Determinantes. Brasil 
IGepec, Toledo, V. 24, n.1, p. 53-72, jan./jun. 2020. 


\section{INTRODUÇÃO}

A discussão do presente artigo tem como eixo norteador reflexões sobre o processo de feminização da pobreza no Brasil. O objetivo é analisar a ocorrência do processo de feminização da pobreza entre os anos 2001 e 2015, investigando suas particularidades em relação a incidência de cor e região, findando com os seus determinantes.

No relatório de Desenvolvimento Humano de 1995 do PNUD foi apresentado um quadro sobre a representação das mulheres na condição de pobreza, compondo $70 \%$ dos pobres do mundo (IPEA, 2005). Neste mesmo estudo, apontou-se alguns fatores que contribuem para o aumento da pobreza nas famílias chefiadas por mulheres, enfatizando as mudanças no comportamento social, com a dissolução dos casamentos, além das inúmeras desvantagens sofridas pelas mulheres na sociedade e no mercado de trabalho.

No Brasil, o percentual da população que estava na condição de pobreza decaiu entre 2001 e 2015 (PNAD 2001, 2015). Entretanto, o que se busca investigar é se a representação feminina nessa condição se intensificou. Costa et al (2005), ao analisarem o intervalo de tempo entre 1983 e 2003, não identificaram o fenômeno da feminização da pobreza no Brasil. Os próprios autores sinalizam que novos estudos devem ser feitos incluindo especialmente o caráter multidimensional da pobreza. Além disso, o intervalo de tempo que este artigo se propõe analisar se difere do que foi analisado pelos autores, constituindo um período no qual se apresenta diferentes políticas públicas voltadas às mulheres (como o Programa "Minha Casa Minha Vida"; "Bolsa Família", etc), intensificando, consequentemente, os lares chefiados por elas, passando de 26\% em 2001 para 42\% em 2015 (PNAD, 2001 e 2015). Ou seja, é uma realidade bastante diferente da analisada por Costa et al (2005).

Ademais, Raiher (2016) identificou um processo de sobre-representação feminina na pobreza no Brasil em 2014, concentrando-se de forma mais abrupta nas regiões Norte e Nordeste, atingindo de forma mais efetiva as mulheres negras, pardas e indígenas. Neste contexto, torna-se importante investigar se há um processo de feminização da pobreza ao longo do tempo no Brasil, ou se apenas foi um caso isolado o fenômeno observado por Raiher (2016) em 2014.

Para isso, este artigo está estruturado em cinco seções, sendo esta inclusa no processo. A segunda seção trata sobre a feminização da pobreza, trazendo elementos que contribuem para o avanço da discussão teórica. Na sequência, tem-se a metodologia. A quarta seção traz a análise acerca da realidade brasileira nos anos de 2001 e 2015, com percentuais de famílias chefiadas por homens e por mulheres, inseridos na condição de pobreza ao longo do tempo, investigando seus determinantes. Por fim, têm-se as considerações finais.

\section{2-POBREZA E A SUA FEMINIZAÇÃO: ELEMENTOS TEÓRICOS}

\subsection{CONDIÇÃO DE POBREZA}

Segundo Costa (2010), a pobreza é resultado de um conjunto de fatores que dificultam o desenvolvimento humano, não resultando de fatores naturais, mas sim, como consequência de uma construção social que perpassa por decisões políticas. Para a autora, os homens constroem o mundo social e são eles que produzem a riqueza e a pobreza humana.

Em sociedades monetarizadas, num contexto de economia de mercado, a definição de pobreza é entendida como insuficiência de renda. Sua mensuração decorre 
da determinação de uma linha de rendimentos monetários. Assim, uma pessoa estaria na condição de pobreza se a sua renda ou os seus gastos de consumo agregados fossem inferiores a um valor estabelecido como necessário para sua sobrevivência. (CARNEIRO, 2005).

No entanto, há muito tempo a referida visão foi ultrapassada. Rocha (2006), a partir dos estudos de Townsend (1962), enfatizou o caráter relativo da noção de pobreza, salientando que a questão não é meramente monetária. Pobreza é privação de capacidades, de oportunidade de escolher "ser", "ser" e "fazer", do mais elementar, como estar bem nutrido, escapar da fraqueza e da mortalidade até as realizações mais complexas e sofisticadas, como ter autoestima e ser uma parte ativa na vida da comunidade. (FLEURY, 1999). Assim, deve ser levado em conta o acesso da população a recursos como: educação, saúde, habitação, assistência social, dentre outros direitos sociais.

É sabido que o Brasil não é um país pobre, e sim um país desigual. Diante disso, refletir sobre a pobreza implica em discutir sobre a multidimensionalidade da categoria, pois a ausência de renda é tão somente o polo visível da pobreza. Pensar na pobreza implica em compreender as diversas nuances que a invisibilidade social traz.

Segundo Delgado (2003), a herança histórica do "mercado de trabalho" e do "mercado de terras", com um modelo de modernização e industrialização no pósguerra, sem mudança das relações sociais, foram os grandes eixos reprodutores da pobreza no país. No mesmo sentido, Silva (2000) e Yazbek (1993) afirmam que a maior causa da pobreza é a acumulação capitalista, gerada por um sistema que acumula riqueza e miséria, expressas na enorme desigualdade social, assinalada por mecanismos de desproteção das classes subalternas.

Sendo assim, a desigualdade social é um fator que contribui para a produção e reprodução da pobreza, dada às características inerentes ao sistema capitalista, ao posicionamento do Estado e do mercado. A desigualdade de gênero reforça o modelo posto e contribui para manutenção da pobreza e exclusão social, de uma parte significativa da população brasileira.

\section{2-GÊNERO E POBREZA}

Embora gênero seja um atributo individual, a pobreza quase sempre é analisada e estudada como uma condição familiar (coletiva). Destarte, eleva-se a relevância do presente estudo, tendo em vista que a desigualdade e a discriminação de gênero são fatores importantes de reprodução da pobreza.

A forma como as mulheres experimentam a pobreza é diferente da dos homens. Sen (2001) traz sete exemplos de desigualdade entre homens e mulheres em um rol não taxativo: desigualdade na mortalidade, na natalidade, das facilidades básicas, desigualdade nas oportunidades, desigualdade profissional, desigualdade na propriedade e desigualdade no lar.

Sobre a discriminação de gênero, esta é baseada nas características da personalidade e comportamento que é dada às pessoas em razão de seu sexo e se baseia na relação do sexo com as características socialmente construídas que fazem com que sejam segregados negativamente, apresentando-se como atribuição cultural. (ARRIAGADA, 2003). Assim, conclui-se, em apertada síntese, que a eliminação das desigualdades sociais e da discriminação existente entre homens e mulheres é um dos objetivos que devem guiar as políticas públicas, para superar a pobreza e seu círculo vicioso futuro. 


\section{3-CONCEITOS DE FEMINIZAÇÃO DA POBREZA}

O termo "feminização da pobreza" foi introduzido por Diane Pearce em 1978, em artigo publicado na Urban and Social Change Review, em que a conclusão principal foi de que a pobreza estaria, cada vez mais, se tornando um problema feminino. A "feminização da pobreza" é uma ideia que remonta à década de 1970 (quando eclodiu o feminismo) e foi popularizada no Brasil no início da década de 1990. Não há um conceito fechado do termo, mas todas as definições direcionam para a ideia de que há um aumento na diferença dos níveis de pobreza entre as mulheres e os homens ou às desigualdades entre homens e mulheres ao longo do tempo.

À partida, importa salientar que o processo da "feminização da pobreza" não é um fenômeno recente e não surgiu na década de 1970 juntamente com o termo, é um processo histórico que provém de inúmeras variáveis, tais como a lógica patriarcal. $\mathrm{O}$ gênero tem sido um fator de diferenciação cultural-valorativa na construção de normas sociais que tem, ao longo dos tempos, privilegiado a masculinidade.

A definição do termo, em análise, necessita dos conceitos de pobreza e de feminização. Conforme já explicado anteriormente, a pobreza é a falta de recursos, capacidades ou liberdades. Feminização é um processo, não é um fenômeno estático. "A feminização é uma ação, um processo de se tornar mais feminina" (MEDEIROS et COSTA, 2008, p.08). Neste sentido, a "feminização da pobreza" constitui o fenômeno de tornar a pobreza com um rosto mais feminino.

Autores, como Medeiros (2008), definem a feminização da pobreza como um aumento dos domicílios "chefiados" por mulheres entre os pobres. Destarte, a referida definição se centra na ideia de mudança dos perfis dos pobres, se concentrando especialmente entre as mulheres.

Uma perspectiva para compreender esse fenômeno, muitas vezes, se articula com os efeitos específicos das políticas econômicas de corte neoliberal sobre a vida e o trabalho das mulheres. Assim, "se a pobreza é reduzida drasticamente entre os homens e apenas ligeiramente entre as mulheres, haveria ainda uma feminização da pobreza" (MEDEIROS et COSTA, 2008, p. 10). Ademais, nos estudos mais recentes (como o relatório da Comissão Econômica para a América Latina e Caribe divulgado em 2016) é identificado grupos de mulheres mais vulneráveis ao empobrecimento, tais como às negras, indígenas, às mulheres lésbicas, as mães solteiras, entre outras.

Para o PNUD (2010) a "feminização da pobreza" é um conceito controverso por agrupar a pobreza e a desigualdade de gênero, duas grandes problemáticas da contemporaneidade. Por essa razão, tem-se a necessidade de se esclarecer o conceito e atribuir indicadores para possibilitar políticas públicas eficientes.

Em suma, o processo de feminização da pobreza consiste no crescimento (absoluto ou relativo) da pobreza no universo feminino. Assim, pode-se chegar a seis definições possíveis do que seja feminização da pobreza, são elas: a) aumento da proporção de mulheres entre os pobres; b) aumento da proporção de pessoas em famílias chefiadas por mulheres entre os pobres; c) aumento absoluto na incidência ou na intensidade da pobreza entre as mulheres; d) aumento nos diferenciais de incidência ou de intensidade da pobreza entre mulheres e homens; e) aumento na incidência ou na intensidade da pobreza entre as pessoas de famílias chefiadas por mulheres; e f) aumento nos diferenciais de incidência ou de intensidade da pobreza entre as pessoas de famílias chefiadas por mulheres e de famílias chefiadas por homens.

A "feminização da pobreza" é um processo, não simplesmente um estado das coisas ou uma conjuntura particular. Aguilar (2011), alerta para o fato de que, na análise do grau de visibilidade da pobreza feminina não se consideram as regras que 
regem a distribuição interna em uma unidade doméstica, e que variam amplamente em sociedades e culturas.

Assim, em regra, a "feminização da pobreza" é relacionada com dois elementos: o aumento da chefia feminina como indicador de pobreza e a inserção das mulheres no mercado de trabalho de forma subalternizada.

Soares (2013), afirma que o debate atual sobre a "feminização da pobreza" não consegue dar conta de compreender/analisar a relação dialética entre 0 aprofundamento da pobreza feminina e a crise do modo de produção capitalista no pós-1970. Por isso, seria necessário atualizar o debate sobre "feminização da pobreza" e a relação do movimento feminista com o Estado, numa perspectiva de totalidade. Dispõe que o conceito de "feminização da pobreza", como está sendo analisado nas últimas décadas, têm uma forte funcionalidade para a lógica do modo de produção capitalista, assim como, não analisa a dominação e exploração das mulheres de forma aprofundada. Em primeiro lugar, porque parte do pressuposto de que a pauperização das mulheres é um processo recente. Em segundo lugar, o processo de aprofundamento da pobreza feminina, deveria ser pensado como parte do processo de empobrecimento da classe trabalhadora no pós 1970. Isso porque, as medidas para retomar o ciclo expansivo e acumulativo do capital nos anos 1980, baseadas no receituário neoliberal, não foram capazes de superar a crise capitalista, entretanto, afetaram a condição de vida da classe trabalhadora.

No Brasil, não houve, de 1983 a 2003 qualquer padrão que representasse a Feminização da Pobreza no país, tendo como exceção somente o aumento na proporção de famílias do tipo "mulher sem cônjuge”, dentre os pobres. O que, para Costa et al (2005) pode significar o simples reflexo das mudanças no padrão demográfico a qual a população passa de tempos em tempos.

Nas próximas seções analisar-se-á as evidências empíricas do processo de feminização da pobreza recente do Brasil, com base em dados da Pnad 2001 e 2015.

\section{3-METODOLOGIA}

Os dados utilizados nessa pesquisa foram extraídos das Pesquisas Nacionais por Amostra de Domicílios (PNADS) - IBGE de 2001 e 2015. Consideraram-se apenas os chefes de domicíliosı para identificar a feminização da pobreza. Nesse sentido, o conceito de feminização utilizado foi o de: "aumento nos diferenciais de incidência ou de intensidade da pobreza entre famílias chefiadas por mulheres e as chefiadas por homens". Ou seja, o processo de feminização da pobreza no Brasil se fará presente se ocorrer um aumento na diferença entre os percentuais de domicílios inseridos na pobreza das mulheres versus o dos homens entre 2001 e 2015.

Para isso, inicialmente, construiu-se uma medida para a pobreza. Usou-se a metodologia de Kageyama e Hoffman (2006) para essa mensuração, a qual não se fixou apenas em uma medida monetária, mas também em aspectos qualitativos dos domicílios. Primeiramente, estabeleceu-se uma linha de pobreza correspondente a

1 Está se considerando chefe do domicílio os indivíduos que se declararam como tal, independente se tinha a presença do cônjuge no domicílio. Entretanto, conforme aponta Cavenaghi e Diniz Alves (2018), no ano de 2015, dos domicílios que se autodeclararam como monoparental, $87 \%$ eram chefiados por mulheres, evidenciando que, quando as mesmas são consideradas chefes, tem-se uma maior probabilidade de não terem o cônjuge presente naquele espaço. 
meio salário mínimo per capita 2 e, como aspectos qualitativos, quatro itens foram avaliados: existência de água encanada, de banheiro, de fogão e de geladeira. Aqueles domicílios que apresentaram renda per capita acima da linha de corte e pelo menos dois itens básicos, foram considerados como não pobres; se os domicílios estavam abaixo da linha de corte, mas detinham quatro ou três itens, foram considerados como Pobre Tipo I; se estavam abaixo da linha de pobreza e tinham três ou dois itens, enquadram-se como Pobre Tipo II, e; se estavam abaixo da linha e tinham um ou nenhum dos itens, foram considerado como extremamente pobre.

Feita essa classificação para 2001 e 2015, usou-se a estatística descritiva visando analisar se de fato vem ocorrendo um processo de feminização da pobreza no Brasil. Na sequência, testou os elementos que impactam na probabilidade de um domicílio adentrar na pobreza (modelo 1 e 1'), estimando, na sequência, os fatores que elevam a probabilidade entre os domicílios femininos de se enquadrar como pobres. Para isso, estimou-se (2 e 2'), via modelo logit.

$$
\begin{gathered}
\ln \left[\frac{p}{1-p}\right]= \\
\begin{aligned}
& b_{0}+b_{1} \text { Gên }+b_{2} \text { Idade }+b_{3} \text { Cor }+b_{4} \text { Escolaridade }+b_{5} \text { Regiao }+ \\
& b_{6} \text { Criancas }+b_{7} \text { Ocupado }+e \\
\ln \left[\frac{p}{1-p}\right]= & b_{0}+b_{1} \text { SexoCor }+b_{2} \text { Idade }+b_{34} \text { Escolaridade }+b_{4} \text { Região }+ \\
& b_{5} \text { Criancas }+b_{6} \text { Ocupado }+e
\end{aligned}
\end{gathered}
$$

Em que: p é a probabilidade de um domicílio estar classificado como Pobre (Tipo I ou Tipo II ou extremamente pobre) e 1-p é a probabilidade de não estar; Sexo é uma proxy utilizada para gênero, sendo composta por uma variável dummy, em que recebeu 1 para mulher e o para homem; Cor é uma dummy para cor, tendo 1 para não branco e o para branco (branco+ amarelo); Região é uma dummy que considera 1 para Norte/Nordeste e o para as demais; Crianças refere-se à presença de criança no domicílio, constituindo de uma dummy, com 1 para a presença e o para a ausência; Ocupado é uma dummy que tem 1 para quem tem algum tipo de trabalho e zero para caso contrário; GênCor é uma dummy que capta se é mulher não branca (1) ou caso contrario (o).

$$
\begin{gathered}
\ln \left[\frac{\mathrm{p}}{1-\mathrm{p}}\right]=\mathrm{b}_{0}+\mathrm{b}_{1} \text { Idade }+\mathrm{b}_{2} \text { Cor }+\mathrm{b}_{3} \text { Escolaridade }+\mathrm{b}_{4} \text { Regiao }+\mathrm{b}_{5} \text { Civil }+ \\
\mathrm{b}_{6} \text { Criancas }+\mathrm{b}_{7} \text { Ocupada }+\mathrm{e} \\
\begin{array}{c}
\ln \left[\frac{\mathrm{p}}{1-\mathrm{p}}\right]= \\
\mathrm{b}_{6} \text { Criancas }+\mathrm{b}_{7} \text { Ocupada }+\mathrm{b}_{7} \text { CorReg }+\mathrm{e}
\end{array}
\end{gathered}
$$

Em que: $\mathbf{p}$ é a probabilidade de um domicílio chefiado por mulher estar classificado como pobre (Tipo I ou Tipo II ou extremamente pobre) e 1-p é a probabilidade de não estar; CorReg é uma dummy em que 1 refere-se a mulher não branca e do Norte/Nordeste, e o casos contrário.

O modelo Logit estima a probabilidade de ocorrência de determinado evento, dado um conjunto de variáveis explicativas. Com os resultados obtidos especialmente

\footnotetext{
2 Ressalta-se que como entre 2001 e 2015 se teve valorização do salario mínimo, então se estipulou um valor de meio salário mínimo para 2001, compatível ao de 2015, ou seja, pegou o valor de meio salário mínimo de 2015 e deflacionou para 2001.
} 
em (2) e (2'), se definem os fatores potenciais da reversão do processo cumulativo negativo da pobreza existente nos domicílios chefiados por mulheres ao longo do país.

\section{4-RESULTADOS E DISCUSSÃO}

\section{1-Feminização da pobreza: análise brasileira}

Com base na metodologia adotada, constatamos que nos últimos anos aumentou o número de domicílios chefiados por mulheres no Brasil. Em 2001, apenas $26 \%$ eram chefiados por mulheres, subindo para 42,2\% em 2015, havendo uma queda significativa no percentual de domicílios chefiados por homens no país (Tabela 1).

Tabela 1: Percentual de domicílios chefiados por Mulheres e Homens - 2001 e 2015

\begin{tabular}{l|r|r}
\hline Sexo do responsável pelo domicílio & 2001 & 2015 \\
\hline Feminino & 26.3 & 42.2 \\
Masculino & 73.7 & 57.8 \\
\hline
\end{tabular}

Fonte: Pnad, com dados organizados pela pesquisa.

Perce (1978), no seu estudo acerca da feminização da pobreza nos Estados Unidos, infere como um dos determinantes do aumento das famílias chefiadas por mulheres às mudanças que se teve no comportamento social, com maior dissolução de casamentos. No Brasil, a partir da década de 1960, presenciou-se o avanço na igualdade entre os sexos e o aumento de separações, havendo a institucionalização da separação e do divórcio. Em 1977, com a Lei 6.515/1977, os relacionamentos insatisfatórios puderam ser rompidos, havendo, a partir do aparato legal, a possibilidade de rompimento desses laços.

Em alguma magnitude, esse marco institucional é importante para explicar a elevação de domicílios chefiados por mulheres no Brasil. Com efeito, o Instituto Brasileiro de Geografia e Estatística (IBGE) (2018) demonstra a evolução que se teve no número de divórcios no país, com uma intensificação desse fenômeno especialmente a partir dos anos de 2000 , com um crescimento de mais de $200 \%$ entre 1990 e 2010.

Segundo Schimanski (2014), nos anos 1970 outras mudanças ocorreram no interior das famílias, como por exemplo, o uso da pílula anticoncepcional. A propagação do seu uso trouxe a separação entre a sexualidade e a reprodução (de modo que a maternidade tornou-se uma opção da mulher), havendo possibilidades de uma maior liberdade em se inserir no mercado de trabalho, bem como, opções para relacionamentos mais íntimos, sem necessariamente estar vinculada a um casamento. Já nos anos de 1980/90, houve a descoberta das fertilizações "in vitro" e as inseminações artificiais. Para a Schimanski (2014), todos esses fatores alteraram substancialmente os padrões sociais de família no Brasil.

Itaboraí (2017) contribuiu com essa discussão, inferindo a existência de intensas mudanças sociais nas condições das mulheres nas famílias brasileiras entre os anos de 1976-2012. Para a autora, destacam-se quatro processos que contribuíram diretamente para que isto ocorresse: o processo de mudança macroestrutural de modernização; os anseios das mulheres por mais autonomia e das famílias por mobilidade social; os movimentos sociais feministas e de classe, e a agenda internacional de direitos das mulheres.

Outro viés da mudança no perfil do responsável pela chefia nas famílias, diz respeito às Políticas Públicas. Alguns movimentos e entidades de mulheres no Brasil colocam a necessidade da mulher ser priorizada nas políticas públicas, devido a sua 
“funcionalização", isto é, pelo "papel” que desempenha na família, pelo efeito multiplicador que a ação pode ter sobre a família e sobre a sociedade como um todo. Ou seja, incluir as mulheres nos Programa Sociais significa romper o círculo vicioso (repetitivo) da pobreza, não só da família no "hoje”, mas, também, de romper com esse processo negativo inerente às futuras gerações. Outro segmento enfatiza a necessidade de inclusão das mulheres nas políticas públicas por se tratar de um espaço de cidadania, ou seja, na constituição da mulher como sujeito social (FARAH, 2004).

A tendência de se colocar na agenda política a questão de gênero sofreu forte influência do feminismo internacional. Os movimentos sociais e entidades de mulheres passaram a recomendar, nas políticas públicas, a discriminação positiva de alguns grupos de mulheres mais atingidas pela exclusão. Nessa discriminação positiva recomendava-se especial atenção às mulheres negras, às mães solteiras e às chefes de família, pelo maior grau de vulnerabilidade destes segmentos.

No ano de 2004, o Governo brasileiro unificou os programas sociais: o auxílio gás, o bolsa alimentação e o bolsa escola. A unificação resultou no Programa Bolsa Família, criado pela Lei 10.836/2004 e regulamentado pelo Decreto 5.209/2004. Este Programa Federal tem por objetivo o atendimento às famílias em situação de pobreza e extrema pobreza, sendo recomendado que o titular responsável deva preferencialmente ser a mulher. No caso do Programa "Minha Casa, Minha Vida", implementado a partir de 2009, a mesma preferência se deu, priorizando a mulher como responsável pelo domicílio para auferir as linhas de financiamento habitacional. Conforme dados divulgados pelo Governo Federal, as mulheres eram proprietárias de 89\% das unidades habitacionais do Programa, demonstrando a valorização da mulher na aquisição da habitação nesse programa (PORTAL BRASIL, 2015).

Acredita-se que a influência do feminismo internacional e o enfoque preferencialmente às mulheres nos programas sociais, podem ter contribuído para que novos arranjos familiares tivessem maior visibilidade, incluindo as famílias chefiadas por mulheres, justificando, em parte, esse aumento no percentual de mulheres chefes dos domicílios brasileiros.

$\mathrm{Na}$ tabela 2, logo a seguir, tem-se o percentual de domicílios que estavam inseridos na condição de pobreza, apresentando sua evolução entre 2001 e 2015, analisando por sexo do responsável pelo domicílio. Observa-se que, tanto no caso dos domicílios chefiados por homens como os chefiados por mulheres, diminuíram o percentual que estavam na condição de pobreza; entretanto, em 2001 o percentual era maior para os homens do que para as mulheres, e, em 2015, reverte-se tal situação, de maneira que o percentual de domicílios na condição de pobreza cujo responsável era do sexo feminino ficou maior do que os que eram chefiados por homens. Este dado aponta para a existência de um processo de feminização da pobreza no Brasil.

Para Matos (2005), a feminização da pobreza está relacionada à questão do trabalho e salários das mulheres. Segundo a autora, as profissões de maior legitimidade e prestígio social continuam sob domínio masculino, mesmo que as mulheres sejam mais escolarizadas do que os homens. Outra variável que se deve analisar quando se aponta para a feminização da pobreza, é a quantidade de crianças no domicílio. Quando ocorre a separação entre os pais, a mulher, em sua maioria, fica com a responsabilidade para com a prole e, por vezes, não consegue uma pensão condizente com as reais necessidades dos filhos. 
Tabela 2: Percentual de domicílios brasileiros inseridos na condição de Pobreza - Por sexo - 2001 e 2015

\begin{tabular}{|c|c|c|c|c|c|c|c|c|c|c|}
\hline \multirow{3}{*}{$\begin{array}{l}\text { Responsáv } \\
\text { el pelo } \\
\text { domicílio }\end{array}$} & \multirow{2}{*}{\multicolumn{2}{|c|}{ Não Pobres }} & \multirow{2}{*}{\multicolumn{2}{|c|}{ Pobres }} & \multicolumn{6}{|c|}{ Pobres } \\
\hline & & & & & \multicolumn{2}{|c|}{ Pobres I } & \multicolumn{2}{|c|}{ Pobres II } & \multicolumn{2}{|c|}{ Extrem. Pobres } \\
\hline & 2001 & 2015 & 2001 & 2015 & 2001 & 2015 & 2001 & 2015 & 2001 & 2015 \\
\hline & & & 54.2 & & 40.9 & & & & & \\
\hline Total & $45 \cdot 77$ & 80.84 & $\begin{array}{r}3 \\
46.3\end{array}$ & $\begin{array}{l}19.16 \\
\mathbf{2 0 . 0}\end{array}$ & 8 & $\begin{array}{l}17.35 \\
18.0\end{array}$ & $\begin{array}{r}11.19 \\
108\end{array}$ & 1.67 & 2.06 & 0.15 \\
\hline Feminino & 53.64 & 79.99 & 6 & $\mathbf{1}$ & 33.79 & 9 & 2 & 1.79 & 1.76 & 0.13 \\
\hline & & & 57.0 & & 43.5 & & 11.3 & & & \\
\hline Masculino & 42.96 & 81.46 & 4 & 18.54 & 5 & 16.81 & 2 & 1.58 & 2.17 & 0.16 \\
\hline
\end{tabular}

Fonte: Pnad, com dados trabalhados pela pesquisa.

Lavinas (2006) ratifica esses fatores, enfatizando a quantidade de filhos como determinante da vulnerabilidade de uma família. Isso se dá, segundo a autora, em virtude das demandas que as crianças implicam, seja na área de educação, saúde, lazer, entre outros. Isto quer dizer que uma criança provoca impacto negativo três vezes maior na probabilidade de uma família ser vulnerável do que a presença de outros dependentes sejam eles adolescentes ou mesmo idosos sem cobertura previdenciária. (SOUZA, 2008).

Ademais, numa sociedade patriarcal, como a brasileira, há prevalência dos papéis sociais, refletindo também na renda das mulheres. Quando inseridas no mercado de trabalho, as mulheres das camadas mais vulnerabilizadas acabam exercendo profissões destinadas ao "cuidado com o outro", como: babás, educadoras, cuidadoras de idosos, cozinheiras, faxineiras, etc, e com ganhos aquém de suas necessidades básicas, refletindo diretamente na renda e na condição de pobreza das famílias.

Analisando a Tabela 2, nas classificações da pobreza (pobres tipo I, pobres II e extremamente pobres), vê-se que houve uma diminuição considerável dos anos de 2001 para 2015, no entanto, a chefia feminina se sobressai à masculina tanto dentre pobres tipo I (18,09\%) como também no pobre tipo II (1,79\%). Somente na classificação extremamente pobres que a chefia masculina prevaleceu em comparação à chefia feminina, mas com uma diferença muito pequena, de apenas 0,03\%. Esses dados ratificam o processo de feminização da pobreza, que vem ocorrendo ao longo do tempo no Brasil.

Ao analisar a Tabela 3, considerando as variáveis: sexo e etnia infere-se que a pobreza além de ter uma sobreposição no sexo feminino, também possui “cor”, com uma intensificação nas famílias chefiadas por mulheres da etnia negra e parda.

Para analisar essa variável não se pode simplesmente realizar uma leitura superficial dos números, mas resgatar historicamente fatos que dão subsídios para uma análise consistente.

O Brasil teve 300 anos de escravidão. Historiadores como Gilberto Freire, antropólogos como Darcy Ribeiro, trataram com muita propriedade sobre essa fase histórica, em que vidas foram ceifadas, confinamentos foram realizados, torturas, violência, subjugação sexual da etnia negra em prol dos senhores de engenho. Após a abolição, em 1888, a realidade não foi muito diferente, não havendo lugar para os "libertos" iniciarem suas vidas. Havia abundância de mão de obra imigrante (financiada pelo poder público), culminando num imenso exército industrial de reserva descartável (os negros).

Segundo dados do IPEA (2011), os negros após a abolição, ficaram jogados à própria sorte. Os ex-escravos, além de serem discriminados pela cor, somavam-se a população pobre e formavam os indesejados dos novos tempos, os deserdados da 
República. A partir de 1890 foram impiedosamente perseguidos os "capoeiras valentões", predominantemente negros e pobres.

Tabela 3: Percentual de domicílios brasileiros inseridos na condição de Pobreza - Por sexo e etnia - 2001 e 2015

\begin{tabular}{|c|c|c|c|c|c|c|c|c|c|c|c|}
\hline \multirow{3}{*}{$\begin{array}{l}\text { Se- } \\
\text { xо }\end{array}$} & \multirow[b]{3}{*}{ Etnia } & \multirow{2}{*}{\multicolumn{2}{|c|}{ Não Pobres }} & \multirow{2}{*}{\multicolumn{2}{|c|}{ Pobres }} & \multicolumn{6}{|c|}{ Pobres } \\
\hline & & & & & & \multicolumn{2}{|c|}{ Pobres I } & \multicolumn{2}{|c|}{ Pobres II } & \multicolumn{2}{|c|}{ Extrem. Pobres } \\
\hline & & 2001 & 2015 & 2001 & 2015 & 2001 & 2015 & 2001 & 2015 & 2001 & 2015 \\
\hline \multirow{5}{*}{ 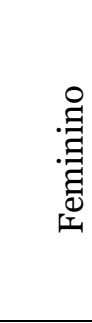 } & Branco & 63.01 & 75.97 & $\begin{array}{r}36.9 \\
9\end{array}$ & $\begin{array}{r}12.0 \\
2\end{array}$ & $\begin{array}{r}29.2 \\
9\end{array}$ & $\begin{array}{r}11.2 \\
0\end{array}$ & 6.82 & 0.78 & 0.88 & 0.03 \\
\hline & & 44.4 & & & 19.2 & 40.8 & 17.4 & & & & \\
\hline & Preto & 9 & $\begin{array}{r}61.55 \\
58.7\end{array}$ & 55.51 & $\begin{array}{r}3 \\
20.6\end{array}$ & $\begin{array}{r}9 \\
39.7\end{array}$ & $\begin{array}{r}7 \\
18.3\end{array}$ & 12.16 & 1.61 & 2.46 & 0.14 \\
\hline & Pardo & 40.13 & $\begin{array}{r}9 \\
74.8\end{array}$ & 59.87 & 1 & 8 & $\mathbf{0}$ & 17.10 & 2.13 & 2.99 & 0.18 \\
\hline & Outros & 72.46 & 2 & 27.54 & 12.59 & 17.51 & 10.15 & 6.90 & 2.44 & 3.13 & 0.00 \\
\hline \multirow{5}{*}{ 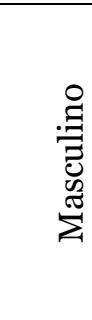 } & & 50.9 & & 49.0 & & 40.9 & 10.8 & & & & \\
\hline & Branco & 5 & $\begin{array}{r}76.54 \\
62.5\end{array}$ & $\begin{array}{r}5 \\
63.3\end{array}$ & 11.73 & $\begin{array}{r}0 \\
48.0\end{array}$ & 8 & $\begin{array}{r}7.17 \\
\mathbf{1 2 . 6}\end{array}$ & 0.77 & 0.98 & 0.08 \\
\hline & Preto & $\begin{array}{r}36.61 \\
30.8\end{array}$ & $\mathrm{o}$ & $\begin{array}{r}9 \\
69.1\end{array}$ & 18.75 & $\begin{array}{r}1 \\
47.2\end{array}$ & 16.99 & $\begin{array}{r}8 \\
17.8\end{array}$ & 1.66 & 2.70 & 0.10 \\
\hline & Pardo & 8 & 61.93 & 2 & 19.04 & 9 & 16.99 & 6 & 1.86 & 3.98 & 0.19 \\
\hline & Outros & 59.59 & 73.97 & $\begin{array}{r}40.4 \\
1\end{array}$ & $\begin{array}{r}13.0 \\
1\end{array}$ & $\begin{array}{r}32.3 \\
5\end{array}$ & $\begin{array}{r}12.4 \\
0\end{array}$ & 6.12 & 0.61 & 1.94 & 0.00 \\
\hline
\end{tabular}

Fonte: Pnad, com dados organizados pela pesquisa.

Em seu livro “O Povo Brasileiro”, Darcy Ribeiro (1999, p. 26) resgata essa parte da história brasileira destacando em um dos trechos que: "[...] negou-lhe a posse de qualquer pedaço de terra para viver e cultivar, de escolas em que pudesse educar seus filhos[...] Grande parte desses negros dirigiu-se às cidades [...] que deram lugar às favelas". Desde então, as favelas vêm se multiplicando, como solução que o pobre encontra para morar e conviver.

Trazendo para a atualidade, isto se reflete consideravelmente nos dias atuais. Largados à própria sorte, os negros e pardos ainda continuam como maioria em nível de pobreza, e no caso feminino, verifica-se a mesma tendência. No entanto, uma ressalva deve se fazer: no caso feminino, em praticamente todos os tipos de "cor" está se tendo um processo de feminização da pobreza", no entanto, a diferença no percentual entre homens e mulheres é maior para os de "cor" preta e parda, o que sinaliza para um processo de feminização da pobreza, especialmente para as famílias chefiadas por negras e pardas.

Analisando a condição de pobreza por região (Tabela 4), visualiza-se uma prevalência na Região Nordeste, tanto no ano de 2001 quanto no ano de 2015. Na maioria dos estados, os índices de domicílios chefiados por homens em condição de pobreza superaram os percentuais femininos em 2001. Para o ano de 2015, o índice de mulheres em condição de pobreza se sobressaiu aos domicílios dos homens, em boa parte dos estados brasileiros, por mais que a condição de pobreza tenha diminuído no Brasil. Apenas em Roraima, Maranhão, Ceará, Rio Grande do Norte, Pernambuco, Alagoas, Rio de Janeiro, Mato Grosso e Distrito Federal, que não se constatou o processo de feminização da pobreza, nos demais, tal processo está ocorrendo.

Ou seja, em 2001 havia 24 estados com predominância dos domicílios chefiados por homens em condição de pobreza e apenas 3 (três) estados com predominância para as mulheres. No ano de 2015, aumentou o número de estados (18) cujos domicílios 
chefiados por mulheres apresentam representatividade na condição de pobreza e caiu para 8 (oito) estados, os domicílios chefiados por homens, nas mesmas condições. Afere-se então que houve um aumento do número de estados com domicílios chefiados por mulheres em condição de pobreza. Isso ratifica o fenômeno da feminização da pobreza que vem ocorrendo no Brasil, com uma intensificação em quase todo o país.

Tabela 4: Percentual de domicílios brasileiros inseridos na condição de Pobreza - Por sexo e Estado - 2001 e 2015

\begin{tabular}{|c|c|c|c|c|}
\hline \multirow[b]{2}{*}{ Estado } & \multicolumn{2}{|c|}{2001} & \multicolumn{2}{|c|}{2015} \\
\hline & $\begin{array}{c}\text { Feminin } \\
0\end{array}$ & Masculino & Feminino & Masculino \\
\hline Rondônia & 62.07 & 70.04 & 21.95 & 20.00 \\
\hline Acre & 69.12 & 68.00 & 41.75 & 34.68 \\
\hline Amazonas & 61.66 & 68.80 & 34.83 & 34.43 \\
\hline Roraima & 62.00 & 71.13 & 25.09 & 30.27 \\
\hline Pará & 61.78 & 72.35 & 35.10 & 34.93 \\
\hline Amapá & 60.18 & 56.72 & 37.03 & 31.20 \\
\hline Tocantins & 55.75 & $65 \cdot 52$ & 24.12 & 21.85 \\
\hline Maranhão & 76.03 & $79 \cdot 38$ & 43.27 & 47.50 \\
\hline Piauí & 65.52 & 80.04 & 36.16 & 35.95 \\
\hline $\begin{array}{l}\text { Ceará } \\
\text { Rio Grande do }\end{array}$ & $63 \cdot 39$ & 77.53 & $35 \cdot 56$ & 35.81 \\
\hline Norte & 58.09 & 69.42 & $\mathbf{2 8 . 6 7}$ & 32.01 \\
\hline Paraíba & 63.69 & 73.61 & 32.15 & 31.94 \\
\hline Pernambuco & 64.51 & 70.90 & 33.27 & 34.30 \\
\hline Alagoas & 68.69 & 77.22 & 46.37 & 48.21 \\
\hline Sergipe & 61.96 & 71.38 & 33.26 & 31.45 \\
\hline Bahia & 62.90 & 71.27 & 32.19 & 29.68 \\
\hline Minas Gerais & 50.17 & 61.22 & 17.28 & 15.99 \\
\hline Espírito Santo & 53.22 & 64.95 & 23.09 & 19.96 \\
\hline Rio de Janeiro & 32.36 & 48.27 & 13.67 & 14.18 \\
\hline São Paulo & 33.76 & 45.07 & 11.90 & 11.42 \\
\hline Paraná & 41.40 & 54.83 & 14.65 & 11.55 \\
\hline Santa Catarina & 29.95 & 40.37 & $7 \cdot 55$ & $7 \cdot 43$ \\
\hline $\begin{array}{l}\text { Rio Grande do Sul } \\
\text { Mato Grosso do }\end{array}$ & 36.59 & 50.36 & 9.66 & 9.28 \\
\hline Sul & 49.26 & 58.19 & $15 \cdot 71$ & 14.34 \\
\hline Mato Grosso & 55.63 & 62.26 & 19.11 & 19.29 \\
\hline Goiás & 53.85 & 67.33 & 18.78 & 16.78 \\
\hline Distrito Federal & 44.57 & 43.59 & 9.25 & 9.94 \\
\hline
\end{tabular}

Fonte: Pnad, com dados organizados pela pesquisa.

Isto posto, após evidenciar a existência do fenômeno de feminização da pobreza - com uma intensificação na etnia negra/parda e na região nordeste-, analisou-se alguns fatores que podem ser responsáveis por esse fenômeno no Brasil. 


\section{2-Determinantes da Feminização da Pobreza no Brasil}

$\mathrm{Na}$ tabela 5 têm-se os fatores determinantes da inserção dos domicílios brasileiros na condição de pobreza. Inicialmente, fez-se uma análise para todos os domicílios, e depois se individualizou apenas para os domicílios chefiados por mulheres.

Observa-se que ser negro/pardo/indígena, na média, eleva em 29\% a chance de inserir um domicílio na condição de pobreza. Ademais, ser da região Norte/Nordeste também intensifica essa probabilidade, em aproximadamente 170\%. Ou seja, características locais dessas duas regiões (como falta de uma estrutura produtiva dinâmica, infraestrutura social, etc.) são elementos que conduzem a uma concentração maior da pobreza - conforme observado anteriormente - e induzem a se ter maior chance de se inserir nessa condição.

A escolaridade e estar ocupado (em termos de trabalho) aparecem como um amortecedor desse processo, em que, cada ano a mais de estudo mínima as chances de se inserir na pobreza em 8\%, e estar ocupado retrai esse percentual em torno de $63 \%$. No caso da educação, diferentes autores, como Mincer (1960), enfocam as melhores oportunidades de emprego que se tem quanto maior é a qualificação da população, obtendo renda maior a cada ano a mais de estudo.

Tabela 5: Coeficientes e Razão de riscos relativos de regressão logística para os determinantes da condição de pobreza - população brasileira - 2015

\begin{tabular}{|c|c|c|c|c|c|c|}
\hline \multirow[t]{2}{*}{ Variaveis } & \multicolumn{2}{|c|}{ Modelo 1} & \multicolumn{2}{|c|}{ Modelo 2} & \multicolumn{2}{|c|}{ Modelo 3} \\
\hline & Coef. & $\begin{array}{l}\text { Razão de } \\
\text { Chances }\end{array}$ & Coef. & $\begin{array}{l}\text { Razão de } \\
\text { chances }\end{array}$ & Coef. & $\begin{array}{l}\text { Razão } \\
\text { Chances }\end{array}$ \\
\hline Sexo (1 feminino; o masculino) & $0.07^{*}$ & 1.08 & $0.05^{*}$ & 1.05 & 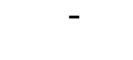 & - \\
\hline Idade & $-0.02^{*}$ & 0.98 & $-0.02^{*}$ & 0.98 & $-0.02 *$ & 0.98 \\
\hline $\begin{array}{l}\text { Cor (1 para } \\
\text { negros/pardos/indígena; o para } \\
\text { demais) }\end{array}$ & $0.26^{*}$ & 1.29 & $0.25^{*}$ & 1.29 & - & - \\
\hline Escolaridade & $-0.08^{*}$ & 0.92 & $-0.08^{*}$ & 0.92 & $-0.09^{*}$ & 0.92 \\
\hline $\begin{array}{l}\text { Região (1 para estados do } \\
\text { norte/nordeste; o para demais) }\end{array}$ & $1.01^{*}$ & 2.74 & $1.00^{*}$ & 2.73 & $1.05^{*}$ & 2.87 \\
\hline Presença de crianças & $0.33^{*}$ & 1.40 & $0.32^{*}$ & 1.39 & $0.33^{*}$ & 1.40 \\
\hline $\begin{array}{l}\text { Ocupado (1 para trabalhando na } \\
\text { semana; o caso contrario) }\end{array}$ & - & - & $-0.38^{*}$ & 0.69 & $-0.37^{*}$ & 0.69 \\
\hline $\begin{array}{l}\text { Dummy Cor e sexo (1 para feminino } \\
\text { e negro/pardo/indig.; o caso } \\
\text { contrário) }\end{array}$ & - & - & - & - & $0.35^{*}$ & 1.36 \\
\hline
\end{tabular}

Fonte: Resultado da Pesquisa

Um último ponto obtido nos resultados da tabela 5 refere-se à dummy de interação entre ser mulher e negra/parda/indígena (modelo 3), a qual se apresentou estatisticamente significativa. Assim, ter essas duas características eleva em $36 \%$ as chances de se inserir na condição de pobreza, de modo que a condição de pobreza é um problema grave especialmente para a mulher negra/parda/indígena no Brasil. É 
importante ressaltar que quando se analisa apenas "ser chefe mulher" (modelo 1) e ser "negro/pardo/indígena" já se tem uma maior probabilidade de inserir na pobreza, no entanto, essa probabilidade se intensifica quando se tem essas duas características conjuntas: ser mulher e ser negra/parda/indígena.

Dada essa constatação e, especialmente, comprovado a existência de um processo de feminização da pobreza, testou-se quais os fatores que elevam a chance das mulheres se inserirem nessa condição. Os resultados encontram-se na Tabela 6.

Quanto maior é a idade das mulheres, menores são as chances de terem privações. Autores, como Struminski e Raiher (2017), comprovam que a aposentadoria minimiza as chances de se efetivar a pobreza. Neste sentido, mulheres mais velhas, especialmente as beneficiárias da previdência, minimizariam as chances de sofrerem privações. Ademais, quanto maior a idade da chefe da família, menos filhos dependentes se têm, e isso flexibiliza mais sua atuação no mercado de trabalho. Assim, aqueles domicílios que tem chefes mais velhas tendem a ter menores chances de se inserirem na pobreza no Brasil.

A escolaridade é outro elemento que retrai essa probabilidade, em que, cada ano a mais de estudo diminui em $29 \%$ a chance de se inserir na condição de pobreza. Percebe-se que esse percentual é o mesmo obtido para a população brasileira como um todo, não se diferenciando para o caso feminino e ratificando sua importância para que, homens ou mulheres, saiam da condição de pobreza.

No caso de estar ocupada, também tem um efeito negativo na probabilidade de ter privações, com a mesma magnitude que a observada para os brasileiros como um todo. Ou seja, ter um trabalho minimiza as chances de se inserir na pobreza.

Uma variável que foi incluída, tendo um impacto negativo na pobreza, refere-se a ser casada, a qual diminui as chances de se inserir na pobreza em torno de $20 \%$. Com efeito, quando a mulher é a chefe de família e está casada tem-se, em geral, uma segunda renda que a ajuda. No caso quando não é casada, apenas uma renda se constitui o alicerce do domicílio, renda a qual, na média brasileira, é menor que a do homem, o que explicaria essa tendência de elevar as chances de sofrer privações. Como se teve um crescimento intenso do número de divórcios, nos últimos anos, justifica-se o seu efeito na elevação da feminização da pobreza.

Também se identificou uma elevação da probabilidade das mulheres se inserirem na pobreza se elas forem das regiões Norte/Nordeste e também se elas forem negras/pardas/indígenas. Quando se constrói uma dummy de interação dessas duas variáveis, o efeito na probabilidade se intensifica significativamente, em que, ser mulher preta/parda/indígena e das regiões Norte/Nordeste aumenta as chances em $145 \%$.

Por fim, um ponto importante que foi analisado nos modelos da Tabela 6 referese à presença de crianças. Naqueles domicílios em que se tem um número maior de crianças, a probabilidade de se inserir na pobreza se intensifica significativamente. A literatura argumenta que ser responsável pelo cuidado com os filhos é um dos principais fatores que induzem as mulheres a estarem em trabalhos mais flexíveis, os quais remuneram menos. Com salários menores e sendo chefe do domicílio, se tem maiores chances de se inserir na condição de pobreza. 
Tabela 6: Coeficientes e Razão de riscos relativos de regressão logística para os determinantes da condição de pobreza Feminina - população brasileira - 2015

\begin{tabular}{|c|c|c|c|c|}
\hline \multirow[t]{2}{*}{ Variáveis } & \multicolumn{2}{|l|}{ Modelo 1} & \multicolumn{2}{|c|}{ Modelo 2} \\
\hline & Coef. & $\begin{array}{l}\text { Razão de } \\
\text { chances }\end{array}$ & Coef. & $\begin{array}{l}\text { Razão de } \\
\text { Chances }\end{array}$ \\
\hline Idade & $-0.02^{*}$ & 0.98 & $-0.02^{*}$ & 0.98 \\
\hline $\begin{array}{l}\text { Cor (1 para negras/pardas/indígenas; o para } \\
\text { demais) }\end{array}$ & $0.26^{*}$ & 1.29 & - & - \\
\hline Escolaridade & $-0.08^{*}$ & 0.92 & $-0.08^{*}$ & 0.92 \\
\hline Presença de crianças & $0.40^{*}$ & 1.47 & $0.40^{*}$ & 1.47 \\
\hline $\begin{array}{l}\text { Região (1 para estados do norte/nordeste; o } \\
\text { para demais) }\end{array}$ & $0.96^{*}$ & 2.62 & - & - \\
\hline $\begin{array}{l}\text { Ocupada (1 para trabalhando na semana; o } \\
\text { caso contrário) }\end{array}$ & $-0.30^{*}$ & 0.74 & $-0.30^{*}$ & 0.74 \\
\hline Estado civil (1 para casado; o caso contrário) & $0.18^{*}$ & 1.20 & $0.21^{*}$ & 1.24 \\
\hline $\begin{array}{l}\text { Dummy cor e Norte/Nordeste ( } 1 \text { para No/Nord } \\
\text { e negras/pardas/indig.; o caso contrário) }\end{array}$ & - & - & 0.89 & 2.45 \\
\hline
\end{tabular}

Fonte: Resultado da Pesquisa

\section{CONSIDERAÇÕES FINAIS}

Ao longo do texto destacou-se que o Brasil possui uma desigualdade social, que culmina no empobrecimento de uma parcela significativa da população. Por mais que os níveis de pobreza diminuíram entre 2001 e 2015, no ano inicial os percentuais de domicílios chefiados por homens apresentavam um nível de pobreza superior ao das mulheres, e em 2015 isso se alterou, ou seja, o percentual de domicílios chefiados por mulheres imersos na condição de pobreza passou a ser maior do que o dos homens. Tal fato comprova a existência de um processo de feminização da pobreza no Brasil.

Ademais, as mulheres negras/pardas/indígenas e especialmente as localizadas no Norte/Nordeste do país são ainda mais vulneráveis nesse processo, com uma intensificação da feminização ainda maior.

Neste contexto, é necessário romper esse processo cumulativo negativo. Para isso, investigou-se quais os fatores poderiam minimizar tal fenômeno. A escolaridade conjugada com a ocupação da mulher tende a amortecer esse processo, conseguindo minimizar a entrada dos domicílios chefiados por mulheres na pobreza. Ao mesmo tempo, tem-se que, quanto maior a presença de crianças nesses domicílios e se a mulher não tiver um companheiro, a probabilidade de estar na condição de pobreza se eleva. Ora, isso reflete a necessidade de apoio, com políticas públicas específicas, com o objetivo de auxiliar as mulheres, dando maior flexibilidade para que busquem empregos com maiores rendas (que em geral são menos flexíveis em termos de horário), com a certeza que seus filhos estão sendo bem cuidados.

Com efeito, o país vem alterando o formato da composição familiar, conjuntamente com novas atribuições da mulher tanto no lar como na sociedade, e as políticas públicas precisam evoluir concomitantemente. A questão é que, não se pode 
manter o formato das políticas que se tinha a priori como sendo suficientes hoje. É necessária uma adequação, tentando melhorar as condições para que a mulher, chefe de família, consiga romper o círculo vicioso da pobreza que ela tende a atrair, gerando bem-estar e um futuro digno para toda a sua família.

\section{REFERÊNCIAS}

ARRIAGADA, I. Dimensiones de la pobreza y políticas desde una perspectiva de género. CEPAL. 2003. Disponível em: <https://www.cepal.org/mujer/reuniones/pobreza/sra_arriagada.pdf>. Acesso em: 23 mai. 2018.

BRASIL. Lei 6515 de 26 de dezembro de 1977. Disponível em: http://www.planalto.gov.br/ccivil_03/Leis/L6515.htm. Acesso em 09/09/2018.

BRASIL. IPEA. GILBERTO Maringoni. História. O destino dos negros após a abolição. disponível em: http://www.ipea.gov.br/desafios/index.php?option=com_content\&id=2673\%3Acati d\%3D28\&Itemid=23. Acesso em 09/09/2018.

BAUDELOT, Christian; ESTABLET, Roger. Allez les filles! Paris: Seuil, 1992.

BIANCHI,Suzanne M. (1999). Feminization and juvenization of poverty: trends, relative risks, causes, and consequences. Annual Review of Sociology, n. 25, p.307-333.

CARNEIRO, C. B. L. Concepções sobre pobreza e alguns desafios para a intervenção social. In Serviço Social e Sociedade. Ano XXV nov. no 84. Ed. Cortez: São Paulo, 2005, p. 66-90.

CAVENAGHI,S; DINIZ ALVES, J. Mulheres chefes de família no Brasil: $\begin{array}{lllll}\text { avanços } & \text { e } & \text { desafios. } & \text { Disponível } & \text { em: }<\end{array}$ http://www.ens.edu.br/arquivos/mulheres-chefes-de-familia-no-brasil-estudosobre-seguro-edicao-32_1.pdf $>$. Acesso agosto 2019.

COSTA. Lúcia Cortes da. O dilema brasileiro da desigualdade social. In: sociedade e cidadania: desafios para o século XXI. $2^{\text {a }}$ ed. Ponta Grossa. Ed. UEPG, 2010.

COSTA. Joana Simões. PINHEIRO, Luana. MEDEIROS, Marcelo. QUEIROZ, Cristina. A face feminina da pobreza: sobre-representação e feminização da pobreza no Brasil. In: Texto para discussão no 1137. IPEA. Brasília, nov, 2005. Disponível em: http://www.ipea.gov.br/portal/index.php?option=com_content\&view=article\&id=4 726 Acesso em 20/10/2018.

DELGADO, G. C. Discursos e Políticas Recentes de Luta contra a Pobreza no Brasil. In: Letienne, B., Milesi, R.; MSCS; Guertechin, T. (Org.). População e Pobreza. o1 ed. São Paulo: Edições Loyola, 2003.

FARAH, Marta Ferreira. Gênero e políticas públicas. In: Estudos Feministas, Florianópolis, jan-abr. 2004. Disponível em: https://periodicos.ufsc.br/index.php/ref/article/view/So104026X2004000100004/7943 Acesso em: 26/03/2018. 
FARIA, Nalu; NOBRE, Mirian. Gênero e desigualdade. São Paulo: SOF, 1997, p.933 .

FLEURY, Sônia. Estado Sem Cidadãos. Seguridade Social na América Latina. 1999. Editora FioCruz. Scielo Books. Disponível em: https://static.scielo.org/scielobooks/jm5wd/pdf/fleury-9788575412428.pdf. Acesso em 10/06/2018.

IBGE. Registro Civil. Disponível em:<https://www.ibge.gov.br/estatisticasnovoportal/sociais/populacao/9110-estatisticas-do-registro-civil.html? $=\& t=0$-quee>. Acesso em out. de 2018.

ITABORAÍ. Nathalie Reis. Mudanças nas famílias brasileiras (1976-2012): uma perspectiva de classe e gênero. $1^{\mathrm{a}}$ ed. Rio de Janeiro: Garamond, 2017.

KAGEYAMA, A.; HOFFMANN, R. Pobreza no Brasil: uma perspectiva multidimensional. Economia e Sociedade, Campinas, v. 15, n. 1 (26), p. 79-112, jan./jun.2006.Disponível

em:<http://www.eco.unicamp.br/docdownload/publicacoes/instituto/revistas/econ omia-e-sociedade/V15-F1-S26/o5-kageyama_hoffmann.pdf $>$. Acesso em 13 de dezembro de 2012.

LAVINAS. Lena; NICOLL, Marcelo. Atividade e vulnerabilidade: quais os arranjos familiares em risco? Dados.v.49, $\mathrm{n}^{0}$ 1. Rio de Janeiro, 2006. Disponível em: http://www.redalyc.org/pdf/218/21849104.pdf. Acesso em 09/09/2018.

MATOS, Marlise. A democracia não deveria parar na porta de casa: a criação dos índices de tradicionalismo e de destradicionalização de gênero no Brasil. In: ARAÚJO, Clara; SCALON, Celi (org). Gênero, família e trabalho no Brasil. Rio de Janeiro: FGV, 2005, p.89-122.

MEDEIROS, Marcelo et COSTA, Joana. Centro Internacional da Pobreza. O que Entendemos por "Feminização da Pobreza"? One pager. Português. Outubro, 2008. Número 58.

MENEZES. Cynara. Darcy Ribeiro explica a desvantagem histórica do negro em relação ao branco. Disponível em: http://www.socialistamorena.com.br/darcyribeiro-explica-a-desvantagem-historica-do-negro/. Acesso em 09/09/2018.

PERROT, Michelle. Mulheres públicas. São Paulo: Ed. Unesp, 1998.

PORTAL BRASIL. Mulheres respondem por maioria das escrituras do Minha

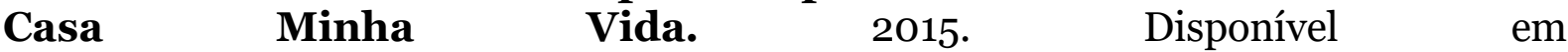
<http://www.brasil.gov.br/infraestrutura/2015/06/mulheres-respondem-pormaioriadas-escrituras-do-minha-casa-minha-vida> . Acesso em nov. 2018.

RAINWATER, Lee. And the poor get children: sex, contraception and family planning in the working class. Chicago: Quadrangle Books, 1960.

RIBEIRO. Darcy. O povo brasileiro: a formação e o sentido do Brasil. Companhia das Letras. $\quad 2^{\mathrm{a}} \quad$ Ed, 1995. Disponível em: 
http://www.iphi.org.br/sites/filosofia_brasil/Darcy_Ribeiro_-_O_povo_Brasileiroa_forma\%C3\%A7\%C3\%A30_e_0_sentido_do_Brasil.pdf. Acesso em 09/09/2018.

ROCHA, Sonia. Pobreza no Brasil: afinal, de que se trata? $3^{\text {a }}$ ed. Rio de Janeiro: Editora FGV, 2006.

SCHIMANSKI, E. Tópicos especiais em assistência social I - Ciclos de vida e políticas específicas para juventude, idosos, mulher, deficientes, negros, índios e orientações sexuais diversas. In: Tópicos Especiais em Assistência Social. Ponta Grossa: UEPG/NUTEAD, p. 7-52, 2014.

SEN. Amartya. O desenvolvimento como liberdade. Tradução Laura Teixeira Mota. São Paulo: Companhia das Letras, 2000.

SILVA, M. M. Condições de vida e estratégias de sobrevivência de famílias em situação de pobreza absoluta. 2000. Dissertação (Mestrado em Política Social) - Universidade de Brasília. 2000.

SOARES. Suamy Rafaely. "Feminização da Pobreza": algumas reflexões sobre o empobrecimento das mulheres. III CEURCA. Colóquio: Sociedade, Políticas Públicas, Cultura e Desenvolvimento. 2013.Disponível em: http://www.ceurca.eco.br/anais/o5_justica_direitos_humanos_e_inclusao_social.p df

SOUZA. Virginia. Famílias monoparentais e vulnerabilidades: uma abordagem a partir dos Centros Municipais de Educação Infantil de Ponta Grossa - PR 2007/2008. Dissertação de Mestrado em Ciências Sociais Aplicadas. Universidade Estadual de Ponta Grossa, 2008. Disponível em:http://tede2.uepg.br/jspui/handle/prefix/277. Acesso em 09/09/2018.

YAZBEK, M. C. Classes subalternas e assistência social. São Paulo:Cortez, 1993. 
Submetido em 27/09/2019

Aprovado em 10/3/2020

\section{Sobre o(s) Autor(es):}

\section{Virginia de Souza}

Assistente Social. Doutoranda do Programa de Pós Graduação em Ciências Sociais Aplicadas pela Universidade Estadual de Ponta Grossa - PR- Brasil. Av Carlos Cavalcanti, 4748- Campus UvaranasPonta Grossa- PR-CEP 84030-900; Mestre em Ciências Sociais Aplicadas- UEPG-(2008); Bacharel em Serviço Social (1996); Especialista em Política de Atendimento à Criança e ao Adolescente (1999); Especialista em Educação Especial (2001). Especialista em Política de Assistência Social - SUAS (2016)UNINTER. Email: vssato@yahoo.com.br

\section{Camila Penteado}

Advogada. Doutoranda do Programa de Pós-Graduação em Ciências Sociais Aplicadas pela Universidade Estadual de Ponta Grossa - PR- Brasil; Av Carlos Cavalcanti, 4748- Campus Uvaranas-Ponta Grossa- PR. Mestre em Direito pela PUC/PR (2011); Especialista em Direito Socioambiental pela PUC/PR (2008). Email: camilapenteadow@gmail.com

\section{Rafaelly do Nascimento}

Jornalista. Mestranda do Programa de Pós Graduação em Ciências Sociais Aplicadas pela Universidade Estadual de Ponta Grossa- PR - Brasil; Av. Carlos Cavalcanti, 4748- Campus Uvaranas-Ponta Grossa- PR. Graduada em Jornalismo pela UEPG (2016).Email: rafaellycel7@gmail.com

\section{Augusta Pelinski Rahier}

Economista, professora do Programa de Ciências Sociais Aplicadas, do Programa de PósGraduação em Economia e do curso de economia na Universidade Estadual de Ponta GrossaPR. Bolsista produtividade-CNPQ. Av. Carlos Cavalcanti, 4748- Campus Uvaranas- Ponta Grossa- PR. Doutora em Economia.

Email: apelinski@gmail.com 